\title{
IRON OXIDE AND PYROCATECHOL: A SPECTROSCOPY STUDY OF THE REACTION PRODUCTS
}

Wagner José Barreto*, Sônia Regina Giancoli Barreto e Ivanira Moreira

Departamento de Química, Universidade Estadual de Londrina, CP 6001, 86051-990 Londrina - PR, Brasil

Yoshio Kawano

Instituto de Química, Universidade de São Paulo, CP 26077, 05513-970 São Paulo - SP, Brasil

Recebido em 3/1/06; aceito em 24/3/06; publicado na web em 1/8/06

\begin{abstract}
The reaction of 1,2-dihydroxy-benzene (pyrocatechol) $\left(\mathrm{C}_{6} \mathrm{H}_{6} \mathrm{O}_{2}\right)$ with iron oxide $\left(\mathrm{Fe}_{2} \mathrm{O}_{3}\right)$ and sodium thiosulfate $\left(\mathrm{Na}_{2} \mathrm{~S}_{2} \mathrm{O}_{3}\right)$ in aqueous medium ( $\mathrm{pH}$ 7) was investigated. Pyrocatechol suffers autoxidation and coordinates with $\mathrm{Fe}^{3+}$ in solution. The presence of $\mathrm{S}_{2} \mathrm{O}_{3}{ }^{2-}$ in solution was fundamental to generate and stabilize the pyrocatechol oxidation products as $o$-semiquinones. This compound was isolated and its structure characterized using FT-IR, EPR and UV-Vis Spectroscopy as [CTA][Fe(SQ) $\left.{ }_{2}(\mathrm{Cat})\right]$. A thermal mass loss mechanism was proposed based on Thermogravimetric Analysis (TG) to support the structural characterization.
\end{abstract}

Keywords: pyrocatechol; iron oxide; sodium thiosulfate.

\section{INTRODUCTION}

Phenolic acids are important components of a variety of processes taking place in soil, including humus formation and accessibility of micronutrients for plants ${ }^{1,2}$. Wang et al. ${ }^{3}$ demonstrated that several phenolic acids in concentrations from 25 to $100 \mathrm{mg} \mathrm{L}^{-1}$, in culture solution, inhibit the growth of several plant cultures. The phenolic substances are important species to maintain the reduction capacity strength in the aquatic medium ${ }^{4}$ and can be generated by microbial processes, lignin degradation or produced by fungi in wood ${ }^{5}$.

The $\mathrm{S}_{2} \mathrm{O}_{3}^{2-}$ is found in fertilizers as a source of sulfur and its chemical reactions in soil are not still completely understood ${ }^{6}$. Most of the studies on $\mathrm{S}_{2} \mathrm{O}_{3}{ }^{2-}$ in soils concern its inhibitor effects on nitrification, urea hydrolysis and also as an effective activator of nitrogen fixation in the environment. $\mathrm{S}_{2} \mathrm{O}_{3}{ }^{2-}$ also can be produced in soil by cysteine degradation or microbial oxidation of elemental sulfur $\left(\mathrm{S}^{\circ}\right)$. The latter process can be generalized through the mechanism:

$\mathrm{S}^{0} \rightarrow \mathrm{S}_{2} \mathrm{O}_{3}^{2-} \rightarrow \mathrm{S}_{4} \mathrm{O}_{6}^{2-} \rightarrow \mathrm{SO}_{3}^{2-} \rightarrow \mathrm{SO}_{4}^{2-}$

There is evidence also for the abiotic oxidation of $\mathrm{S}^{0}$ and $\mathrm{S}_{2} \mathrm{O}_{3}{ }^{2-}$ in soils, although the importance of this process in relation to the global oxidation is not clear ${ }^{7}$. The interaction of iron with phenolic substances in aqueous medium has hardly been studied ${ }^{1,8}$. Although there are several studies on phenolic compounds and manganese reactions in solution $^{9-11}$, it is possible to consider that the phenolic substances can react with iron and manganese through similar mechanisms in soil. Lehmann ${ }^{1}$ has shown, using normal and pre-treated soils with Fe and $\mathrm{Mn}$ as substrate, that the phenolic acids were oxidized simultaneously with the reduction of iron and manganese oxides.

Studies carried out by Barreto et al. ${ }^{12}$, showed that catecholamine, mainly dopamine and adrenaline, were oxidized quickly in aqueous medium in the presence of $\mathrm{MnO}_{2}$ and sodium thiosulfate without producing melanin as the end product. In that mechanism it was proposed and pointed out that the outstanding presence of thiosulfate in the stabilization of surface compounds occurred in the first reaction steps. Barreto et al. ${ }^{13}$ showed that $\mathrm{MnO}_{2}$ oxidized dopamine or L-dopa, in aqueous solution in the presence of sodium

*e-mail: barreto@uel.br thiosulphate. Highly stable $\mathrm{Mn}(\mathrm{II})$ complexes were generated in this process that could be precipitated with cetyltrimethylammonium bromide. The complexes obtained were characterized as $[\mathrm{CTA}]\left[(\mathrm{Mn})(\mathrm{SQ})_{3}\right]$ and presented an octahedral-type structure, where the SQ ligands were dopamine-o-semiquinone or L-dopa-osemiquinone anionic radicals; products of dopamine or L-dopa oxidation. These complexes present the property of maintaining the SQ radical ligands in a stable condition when in contact with air, unlike other complexes of the same type.

The iron complex formation has been studied with various catecholate and semiquinonate ligands ${ }^{14-19}$.

Pyrocatechol is the simplest molecule of the $o$-phenols and is useful as a model molecule to verify which are its reaction products in a reducing medium: polymeric compounds, such as humic acids in soil, or stabilizers such as monomeric compounds.

The objectives of this study were to characterize and propose the thermal decomposition mechanism for the compound obtained by the reaction of 1,2-dihydroxy-benzene (pyrocatechol) $\left(\mathrm{C}_{6} \mathrm{H}_{6} \mathrm{O}_{2}\right)$ with iron oxide $\left(\mathrm{Fe}_{2} \mathrm{O}_{3}\right)$ and sodium thiosulfate $\left(\mathrm{Na}_{2} \mathrm{~S}_{2} \mathrm{O}_{3}\right)$ in aqueous medium at $\mathrm{pH}$ 7.0.

\section{EXPERIMENTAL PART}

\section{Solutions}

All solutions were prepared with ultra pure water.

The reaction mixture containing pyrocatechol, iron oxide and sodium thiosulfate was prepared by adding $0.300 \mathrm{~g}$ sodium thiosulfate $\left(6.32 \times 10^{-3} \mathrm{~mol} \mathrm{~L}^{-1}\right), 0.100 \mathrm{~g}$ pyrocatechol $\left(3.03 \times 10^{-3} \mathrm{~mol}\right.$ $\left.\mathrm{L}^{-1}\right)$ and $0.020 \mathrm{~g}$ iron oxide $\left(4.17 \times 10^{-4} \mathrm{~mol} \mathrm{~L}^{-1}\right)$ to $300 \mathrm{~mL}$ water. The flasks containing the reaction mixture were covered with PVC film to avoid evaporation loss or dust contamination, and maintained under constant stirring at $25^{\circ} \mathrm{C}$. Before each UV-Vis and $\mathrm{pH}$ measurements, stirring was interrupted for $15 \mathrm{~min}$ for the iron oxide to sediment.

\section{UV-Vis and pH measurements}

After the addition of sodium thiosulfate and pyrocatechol to the water, the solution was stirred for $20 \mathrm{~min}$ and the $\mathrm{pH}$ measured. 
$200 \mu \mathrm{L}$ of the solution was diluted to $3 \mathrm{~mL}$ in a quartz cuvette of $1.0 \mathrm{~cm}$ optical path. The UV-Vis absorption spectrum was obtained from 200 to $900 \mathrm{~nm}$ with $1 \mathrm{~nm}$ resolution for each acquisition point. Iron oxide was added to the initial solution, stirred and the $\mathrm{pH}$ and UV-Vis spectra obtained at specific times.

\section{Preparation of the solid compound from the solution}

After disappearance of the $275 \mathrm{~nm}$ band, indicating the total pyrocatechol oxidation, the mixture was centrifuged for $40 \mathrm{~min}$ at $6,000 \mathrm{rpm}$ to remove the iron oxide residue. To the solution was slowly added $10 \mathrm{~mL}$ of cetyltrimethylammonium bromide solution (0.027 $\left.\mathrm{mol} \mathrm{L}^{-1}\right)$ and stirred to complete precipitation. The solution was then transferred to a $500 \mathrm{~mL}$ separation funnel and $50 \mathrm{~mL}$ of chloroform was added. The suspension was stirred and the organic phase separated and washed with ultra pure water for complete elimination of cetyltrimethylammonium bromide. The organic phase was separated and evaporated at room temperature. A dark violet solid was obtained and kept in a desiccator for analysis. The analysis of $[\mathrm{CTA}]\left[\mathrm{Fe}(\mathrm{SQ})_{2}(\mathrm{Cat})\right] .5 \mathrm{H}_{2} \mathrm{O}$ where iron is $\mathrm{Fe}^{3+}, \mathrm{SQ}=o$-semiquinone radical anion, $\mathrm{Cat}=$ catecholate, $[\mathrm{CTA}]=$ cetyltrimethylammonium cation, was found (calculated): $\mathrm{C}=58.4$ (57.6)\%; $\mathrm{H}=9.2$ (8.7)\%; $\mathrm{N}=3.2$ (3.6)\%; $\mathrm{Fe}=7.4$ (7.3)\%. All experiments to crystallize the complex failed and instead produced an amorphous solid probably due to the long aliphatic chain present in CTA cation that prevent a regular crystal arrangement.

\section{Physical measurements}

The IR spectra of the solid compounds were obtained from 400 to $4,000 \mathrm{~cm}^{-1}$ with a spectral resolution of $4 \mathrm{~cm}^{-1}$ and 80 spectra accumulated (Shimadzu Spectrophotometer) using $\mathrm{KBr}$ tablets (Carlo Erba, $99 \%$ ) with 1:100 sample: $\mathrm{KBr}$ proportion.

EPR experiments were performed near the X-band $(9.5 \mathrm{GHz})$ microwave frequency and with a magnetic field modulation of 100 $\mathrm{kHz}$ using Spectrometer Varian E-109 at room temperature. The microwave frequency was accurately read with a Hewlett Packard frequency counter, model HP 5352B. The data were acquired with a PC microcomputer using software for data acquisition developed at the Institute of Physics, University of São Paulo, São Carlos-SP, Brazil.

An iron hollow cathode lamp at $248.33 \mathrm{~nm}$ was used for iron analysis by AAS (Shimadzu AA-6601F Spectrometer). The calibration curve was constructed with an iron standard solution (Merck-1,000 ppm) from 0.1 to $1.0 \mu \mathrm{g} \mathrm{L}^{-1}$ in $1 \%(\mathrm{v} / \mathrm{v})$ nitric acid. Samples (4 mg) were digested with $0.2 \mathrm{~mL}$ of $\mathrm{HNO}_{3}$ (Merck $65 \%$ ) and diluted with $\mathrm{HNO}_{3} 1 \%$ to $50 \mathrm{~mL}$ in a volumetric flask.

Mass losses (Thermogravimetric Analysis) were obtained on a T. A. Instruments TG 2950, High Resolution device under a $\mathrm{N}_{2}$ atmosphere and a heating rate of $10{ }^{\circ} \mathrm{C} \mathrm{min}^{-1}$.

\section{RESULTS AND DISCUSSION}

\section{Study of the reaction in solution}

Figure 1A shows the UV-Vis spectra of reagent mixture during the reaction. A band at $275 \mathrm{~nm}$ characteristic of pyrocatechol was observed at $\mathrm{t}=0$ (spectrum a) and after $432 \mathrm{~h}$ this band disappeared, and a band at $287 \mathrm{~nm}$ and a shoulder at $301 \mathrm{~nm}$ (spectrum e) appeared. The $\mathrm{pH}$ during this period changed from 6.50 to 8.20 , Figure 1B.

The accentuated $\mathrm{pH}$ increase indicated that an oxidation reaction of pyrocatechol occurred with release of $\mathrm{OH}^{-}$and had the same pattern as observed by Barreto et al. ${ }^{12}$ for catecholamine (dopamine, adrenaline, noradrenaline and L-dopa) oxidation reactions with
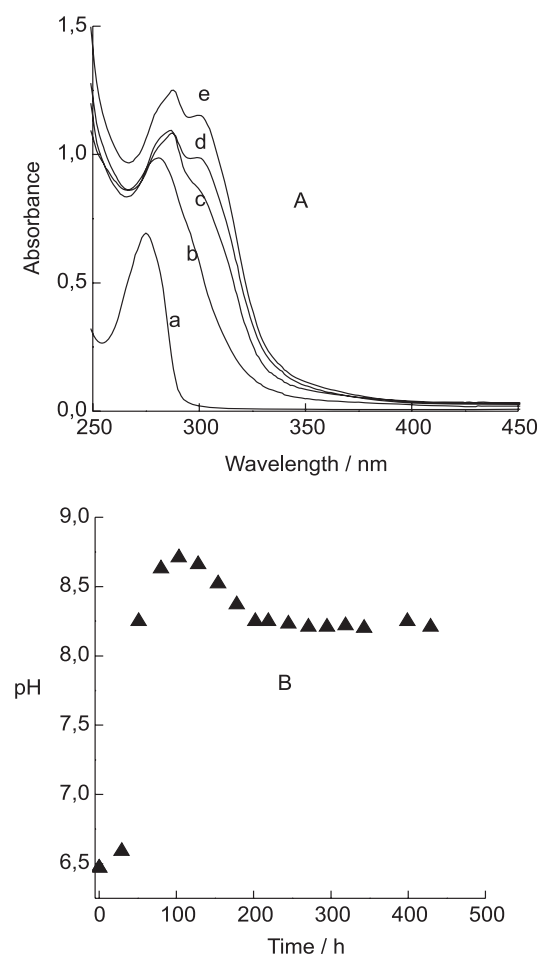

Figure 1. (A) UV-Vis spectra and (B) $p H$ changes of the reagent solution containing pyrocatechol, sodium thiosulfate and iron oxide in the reaction times; $0 h(a), 76 h(b), 186 h(c), 263 h(d) 432 h(e)$

$\mathrm{MnO}_{2}$. However, it was observed that the reaction time for $\mathrm{Fe}_{2} \mathrm{O}_{3}$ was considerably higher compared to $\mathrm{MnO}_{2}$ in the ratio of $1: 14$. In the presence of sodium thiosulfate the intermediate o-semiquinone was stabilized preventing further oxidation steps. In the absence of thiosulfate the oxidation of the pyrocatechol produces the melanin polymer and the solution presents an UV-Vis spectrum with continuum absorption and without band structures.

Pyrocatechol oxidation in the presence of thiosulfate indicated a complex mechanism probably due to intermediary compounds generated during the long reaction time. The results suggested a minor role for $\mathrm{Fe}_{2} \mathrm{O}_{3}$ as an oxidizing agent in the pyrocatechol oxidation reaction compared to that of $\mathrm{MnO}_{2}$ in catecholamine oxidation.

\section{Study of reaction products isolated in the solid state}

The EPR technique applied to the reaction products isolated in solid state from the solution, revealed the presence of $\mathrm{Fe}^{3+}$. Figure 2 shows two spin transitions, the first with $g=4.3$ characteristic of

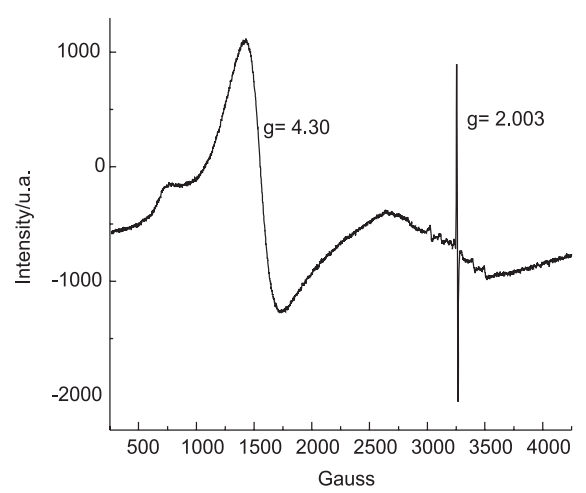

Figure 2. EPR spectrum of the solid complex obtained from the reaction solution with pyrocatechol, sodium thiosulfate and iron oxide 
$\mathrm{Fe}^{3+}$ high spin in a rhombic environment and the other with $\mathrm{g}=$ 2.003 , assigned to the organic free radical $o$-semiquinone. In the solid complex six weak signals around $\mathrm{g}=2$ characteristic of $\mathrm{Mn}^{2+}$ could be observed, probably present as trace impurities in the iron oxide. However, the presence of soluble $\mathrm{Mn}^{2+}$ in the mixture was tested and it had no influence on the oxidative process.

The literature reports that iron(III)-SQ complexes show strong antiferromagnetic spin-spin coupling of Fe-SQ or SQ-SQ, therefore they should be EPR silent ${ }^{14,17}$. A more recent paper, however, reports that unlike the previously characterized mixed valence semiquinonecatecholato-iron(III) complexes, the complex [Fe(III) (bispicen) $\left.\left(\mathrm{Cl}_{4} \mathrm{Cat}\right)\left(\mathrm{Cl}_{4} \mathrm{SQ}\right)\right]$.DMF (bispicen $=N, N$-bis (2-pyridylmethyl) $-1,2$ ethanediamine) is EPR active, presenting at room temperature two broad transitions centered at $g=1.92$ and 2.53 , and a strong signal appears at $77 \mathrm{~K}$ of $\mathrm{g}=4.3$ typical for the high spin $\mathrm{Fe}(\mathrm{III})$ complexes $^{20}$. We believed that the mixed nature of the complex, with $\mathrm{SQ}^{-}$and $\mathrm{Cat}^{2-}$, resulted in weaker spin-spin coupling at room temperature and iron EPR signal appearing.

The presence of $\mathrm{Fe}^{3+}$ in the complex can be explained by the slow released of $\mathrm{Fe}^{3+}$ from the oxide into solution. Jewett et al. ${ }^{21}$ observed the formation of $\mathrm{Fe}^{3+}$ :catechol, in the proportion 1:3 in aqueous solution in $\mathrm{pH}>8.0$, and of the compound $\mathrm{Fe}^{2+}$ :catechol, in the proportion $1: 2$, below that value. As the $\mathrm{pH}$ in the reacting solution was always $>8.0$, increasing even more around $100 \mathrm{~h}$ (Figure 1B), the Fe-SQ-CAT complex had the physical chemical conditions to be present. The UVvis spectrum of the complex in chloroform, Figure 3, presents one transition at $313 \mathrm{~nm}$ assigned to internal ligand electronic transitions and at $514 \mathrm{~nm}$ assigned to an interligand charge transfer $(\mathrm{SQ} \rightarrow \mathrm{Cat})$, or a ligand to metal charge transfer (LMCT).

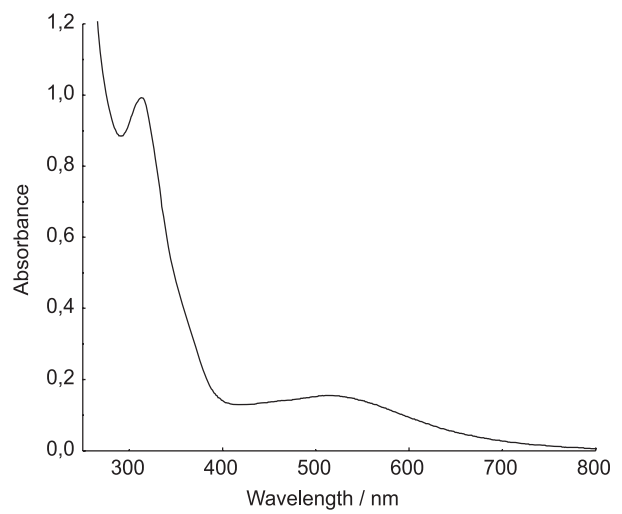

Figure 3. $\mathrm{UV}$-Vis spectrum of $[\mathrm{CTA}]\left[\mathrm{Fe}(\mathrm{SQ})_{2}(\mathrm{Cat})\right]$ complex in $\mathrm{CH}_{3} \mathrm{Cl}$

The spectrum was very similar to $\mathrm{LFe}^{\mathrm{III}}(\mathrm{DBSQ})$, where $\mathrm{L}$ is a phenolate and DBSQ a semiquinonate, showing a band at $560 \mathrm{~nm}$ assigned as LMCT phenolate $\rightarrow \mathrm{Fe}$ (III) and a intense band at 290 $\mathrm{nm}$ to $\pi \rightarrow \pi^{*}$ transition in the ligand ${ }^{22}$. The UV-Vis spectrum of $\left[\mathrm{LFe}^{\mathrm{III}}(\mathrm{DBC})\right]^{-}$, however, showed bands at 620 and $420 \mathrm{~nm}$, typical of catecholate complexes. Therefore, the UV-Vis spectral pattern indicated that the solid compound contained a semiquinone derivative from pyrocatechol and coordenated to high spin iron(III).

The iron complex bands in the infrared spectrum can only be observed from 1000 to $1450 \mathrm{~cm}^{-1}$ due to the predominance of cetyltrimethylammonium cation bands between 400 and $4000 \mathrm{~cm}^{-1}$, Figure 4. Furthermore, Table 1 presents the observed frequencies and a tentative assignment for the compound. Intense bands were observed at 636, 1027, and $1220 \mathrm{~cm}^{-1}$ and a medium band at 1439 $\mathrm{cm}^{-1}$ for the compound obtained in the presence of iron oxide. The bands at 1220 and $1439 \mathrm{~cm}^{-1}$ are characteristic for the ligand based mixed valence semiquinone-catecholate transition metal complexes, while bands at 1100 and $1480 \mathrm{~cm}^{-1}$ were generally observed for catecholates based transition metal complexes ${ }^{22}$. The presence of the band at $1439 \mathrm{~cm}^{-1}$ can be assigned to C-O stretching (vCO) with the iron bonded to the pyrocatechol oxygen.

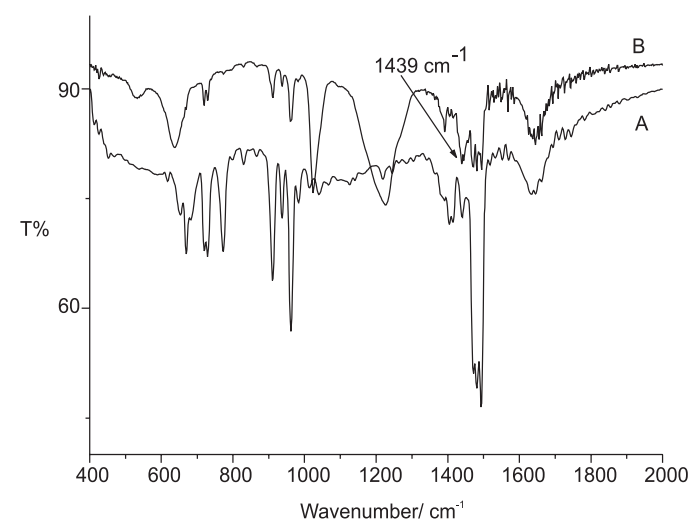

Figure 4. IR spectra of (A) CTAB salt, and (B) [CTA][Fe(SQ)2(Cat)] complex in $\mathrm{KBr}$ pellets

Table 1. Observed frequencies $\left(\mathrm{cm}^{-1}\right)$ and a tentative assignment for the most characteristic bands of $[\mathrm{CTA}]\left[\mathrm{Fe}(\mathrm{SQ})_{2}(\mathrm{Cat})\right]$

\begin{tabular}{ll}
\hline Assignment & Frequency/cm ${ }^{-1}$ \\
\hline$v(\mathrm{CO})+v(\mathrm{CC})$ & $1439 \mathrm{~m}$ \\
$v(\mathrm{CO})+v(\mathrm{CH})$ & $1387 \mathrm{w}$ \\
$v(\mathrm{CO})$ & $1220 \mathrm{~s}$ \\
$v(\mathrm{CO})+v(\mathrm{CC})$ & $1164 \mathrm{sh}$ \\
$v(\mathrm{CC})$ & $1027 \mathrm{~s}$ \\
$v(\mathrm{CC})$ ring $+v(\mathrm{CO}-\mathrm{Fe})$ ring & $636 \mathrm{~s}$ \\
$v(\mathrm{CC})$ ring $+v(\mathrm{C}-\mathrm{O}-\mathrm{Fe})$ ring & $530 \mathrm{w}$ \\
\hline
\end{tabular}

$\mathrm{m}=$ medium, $\mathrm{w}=$ weak, $\mathrm{s}=$ strong, $\mathrm{sh}=$ shoulder

The thermal analysis of the complex was obtained, Figure 5, and the thermal decomposition mechanism below was proposed:

\begin{tabular}{|c|c|c|}
\hline$[\mathrm{CTA}]\left[\mathrm{Fe}(\mathrm{SQ})_{2}(\mathrm{Cat})\right] \cdot 5 \mathrm{H}_{2} \mathrm{O}$ & $\rightarrow[\mathrm{CTA}]\left[\mathrm{Fe}(\mathrm{SQ})_{2}(\mathrm{Cat})\right]+5 \mathrm{H}_{2} \mathrm{O}$ & $\mathrm{T}=50^{\circ} \mathrm{C}$ \\
\hline$[\mathrm{CTA}]\left[\mathrm{Fe}(\mathrm{SQ})_{2}(\mathrm{Cat})\right]$ & $\rightarrow\left[\mathrm{Fe}(\mathrm{SQ})_{2}(\mathrm{Cat})\right]+\mathrm{CTA}$ & $\mathrm{T}=226^{\circ} \mathrm{C}$ \\
\hline$\left[\mathrm{Fe}(\mathrm{SQ})_{2}(\mathrm{Cat})\right]$ & $\rightarrow[\mathrm{Fe}(\mathrm{Cat})]+2 \mathrm{SQ}$ & $\mathrm{T}=277^{\circ} \mathrm{C}$ \\
\hline$[\mathrm{Fe}(\mathrm{Cat})]$ & $\rightarrow$ iron oxide + Cat & $\mathrm{T}=297^{\circ} \mathrm{C}$ \\
\hline & iron oxide (residue) & $\mathrm{T}>550^{\circ} \mathrm{C}$ \\
\hline
\end{tabular}

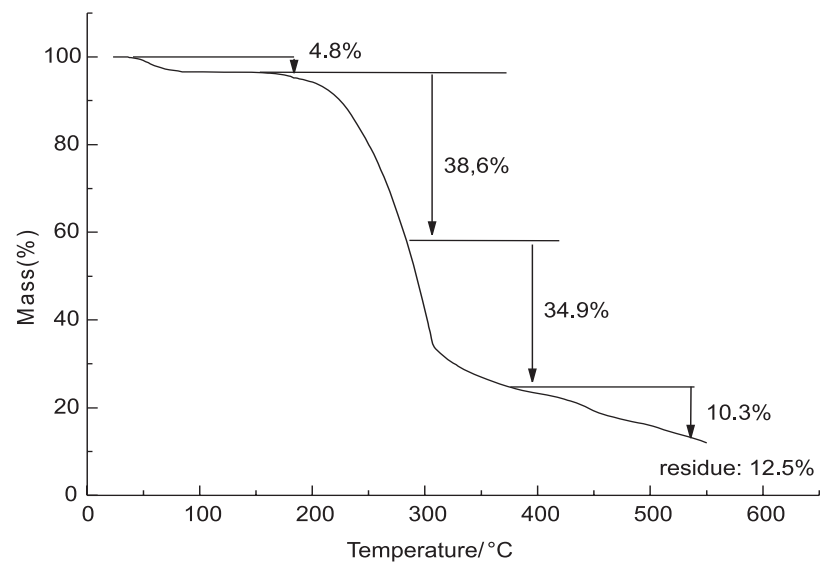

Figure 5. Thermogravimetric curves (TG) for the compound [CTA] $\left[\mathrm{Fe}(\mathrm{SQ})_{2}(\mathrm{Cat})\right]$ 
The mass loss percentages calculated based on the proposed mechanism and experimental results obtained were, respectively, 11.9 and $4.8 \% ; 37.6$ and $38.6 \% ; 42.9$ and $45.3 \%$ and $7.6 \%$ (calculated as $\mathrm{Fe}_{2} \mathrm{O}_{3}$ ) and $12.5 \%$. Steps 3 and 4 steps were summed because the differences between the two mass losses were not well defined. The differences among the calculated and experimental values were due to imprecision in the step interval measurements. The mass loss mechanism reinforced the definition of the proposed structure as presented in Figure 6.

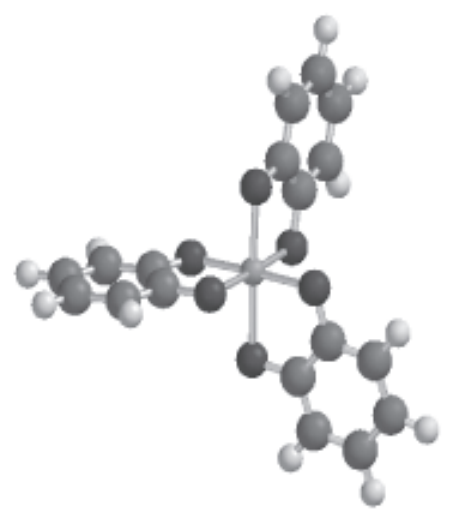

Figure 6. A schematic structure proposed for the anion complex $\left[\mathrm{Fe}(\mathrm{SQ})_{2}(\mathrm{Cat})\right]^{1-}$

\section{CONCLUSION}

The results of pyrocatechol oxidation in the presence of $\mathrm{Fe}_{2} \mathrm{O}_{3}$ and sodium thiosulfate indicated that pyrocatechol was oxidized by a more complex mechanism compared to catecholamine oxidation (dopamine or L-dopa) with $\mathrm{MnO}_{2}$. The presence of $\mathrm{S}_{2} \mathrm{O}_{3}{ }^{2-}$ was fundamental to generate and stabilize the $o$-semiquinones in solution. The presence of the iron oxide provided $\mathrm{Fe}^{3+}$ to stabilize the radical by complex formation and had little action as an oxidizing agent. The complex isolated in solid state through CTAB precipitation indicated the presence of free radicals and $\mathrm{Fe}^{3+}$, and the formulae was proposed as [CTA] $\left[\mathrm{Fe}(\mathrm{SQ})_{2}(\mathrm{Cat})\right]$. The complex structure should be close to an hexacoordenate arrangement with $\mathrm{Fe}^{3+}$ high spin due to the $g=4.3$ characteristic signal. The structure proposed was coherent with the thermal decomposition analysis of the solid complex and associated thermal mechanism.

\section{ACKNOWLEDGEMENTS}

The authors thank Dr. O. R. do Nascimento (Laboratorio de Biofísica UFScar, São Carlos, Brazil) for EPR spectra. The authors thank the CNPq and Fundação Araucária for financial support and Dr. R. Dekker for the manuscript revision.

\section{REFERENCES}

1. Lehmann, R. G.; Cheng, H. H.; Harsh, J. B.; Soil Sci. Soc. Am. J. 1987, 51, 352.

2. Aiken, G. R. In Geochemistry, isolation and characterization; Aiken, G. R.; Mcknight, M. D.; Wershaw, R. L.; MacCarthy, P., eds.; John Wiley \& Sons: New York, 1985, p. 363-385.

3. Wang, T. S. C.; Yang, T. K.; Chuang, T. T.; Soil Sci. 1967, 103, 239.

4. Norwood, D. L.; Johnson, J. D.; Christman, R. F.; Hass, J. R.; Bobenrieth, M. J.; Environ. Sci. Technol. 1980, 14, 187.

5. Goodell, B.; Jellison, J.; Liu, J.; Daniel, G.; Paszczynski, A.; Fekete, F.; Krishnamurthy, S.; Jun, L.; Xu,; J. Biotechnol. 1997, 53, 133.

6. Barbosa-Jefferson, V. L.; Zhao, F. J.; McGrath, S. P.; Magan, N.; Soil Biol. Biochem. 1998, 30, 553.

7. McCarty, G. W.; Bremner, J. M.; Krogmeier, M. J.; Commun. Soil. Sci. Plant Anal. 1991, 22, 755.

8. Pracht, J.; Boenigk, J.; Isenbeck-Schroter, M.; Keppler, F.; Scholer, H. F.; Chemosphere 2001, 44, 613.

9. Stone, A. T.; Morgan, J. J.; Environ. Sci. Technol. 1984, 18, 617.

10. Matocha, C. J.; Sparks, D. L.; Amonette, J. E.; Kukkadapu, R. K.; Soil Sci. Soc. Am. 2001, 65, 58.

11. Bertino, D. J.; Zepp, R. G.; Environ. Sci. Technol. 1991, 25, 1267.

12. Barreto, W. J.; Barreto, S. R. G.; Santos, M. A.; Schimidt, R.; Paschoal, F. M. M.; Mangrich, A. S.; de Oliveira, L. F. C.; J. Inorg. Biochem. 2001, 84, 89.

13. Barreto, W. J.; Barreto, S. R. G.; Kawano, Y.; de Oliveira, L. F. C.; DiMauro, E.; Paschoal, F. M. M.; Monatsh. Chem. 2003, 134, 1545.

14. Attia, A.S.; Conklin, B. J.; Lange, C. W.; Pierpont, C. G.; Inorg. Chem. 1996, $35,1033$.

15. Jô, D.H.; Chiou, Y. M.; Que, L.; Inorg. Chem. 2001, 40, 3181.

16. Kawabata, T.; Schepkin, V.; Haramaki, N.; Phadke, R. S.; Packer, L.; Biochem. Pharmacol. 1996, 51, 1569.

17. Pierpont, C. G.; Coord. Chem. Rev. 2001, 219, 415.

18. Pierpont C. G.; Coord. Chem. Rev. 2001, 216, 99.

19. Barreto W. J.; Barreto S. R. G.; Ponzoni S.; Kawano Y.; DiMauro E.; Magosso H. A.; Silva, W. P.; Monatsh. Chem. 2005, 136, 701.

20. Shaikh, N.; Goswami, S.; Panja, A.; Wang, X-Y.; Gao, S.; Butcher, R. J.; Banerjee, P.; Inorg. Chem. 2004, 43, 5908.

21. Jewett, S. L.; Eggling, S.; Geller, L.; J. Inorg. Biochem. 1997, 66, 165.

22. Mialane, P.; AnxolabehereMallart, E.; Blondin, G.; Nivorojkine, A.; Guilhem, J.; Tchertanova, L.; Cesario, M.; Ravi, N.; Bominaar, E.; Girerd, J. J.; Munck, E.; Inorg. Chim. Acta 1997, 263, 367. 